\title{
Águas pluviais urbanas: integração da drenagem sustentável ao Plano Diretor De Desenvolvimento Urbano (PDU) ${ }^{1}$
}

\section{Urban stormwater: integrating sustainable drainage and Cities Master Plans}

\author{
Guerra, Rodrigo Augusto'; Gonçalves, Luciana Marcia² \\ 1 Programa de Pós-Graduação em Engenharia Urbana da Universidade \\ Federal de São Carlos, São Carlos/SP, Brasil, rodrigoaguerra@gmail.com \\ 2 Programa de Pós-Graduação em Engenharia Urbana da Universidade \\ Federal de São Carlos, Araraquara/SP, Brasil, arq.Iuciana.ufscar @gmail.com
}

\begin{abstract}
RESUMO
A relação homem-água passou por diferentes momentos no decorrer dos anos e a atual rejeição à sua presença em espaços urbanos é um reflexo das políticas higienistas, que apontavam a água em ambientes urbanos como vetor de epidemias e mau cheiro, o que, na realidade, relacionava-se à falta de manutenção e desuso do sistema, resultando em águas pluviais e cloacais escorrendo pelas ruas. A solução, na época, foi escondê-la e canalizá-la, ações estas que geram impactos até hoje. Os sistemas tradicionais, juntamente à alta taxa de urbanização e impermeabilização do solo, são insuficientes ao grande volume escoado, ocasionando inundações e danos. Abordagens alternativas de manejo das águas pluviais têm demonstrado resultados superiores a este, como a aplicação complementar de técnicas compensatórias e princípios do desenvolvimento de baixo impacto (LID). Este artigo resulta em uma revisão técnico-conceitual da drenagem pluvial urbana alternativa e sua relação com o desenvolvimento citadino, representado pelos Planos Diretores de Desenvolvimento Urbano. A maioria das cidades brasileiras vê o manejo das águas como objeto de planos complementares, dificultando a execução eficiente e premeditada durante o desenvolvimento urbano, muitas vezes gerando impactos ambientais, sociais e econômicos.
\end{abstract}

Palavras-chave: Águas pluviais, Drenagem urbana, Drenagem sustentável, Planejamento urbano, Plano de Desenvolvimento Urbano.

\begin{abstract}
The man-water relationship has passed through different moments over the years, and the current repudiation for its presence in urban spaces is a reflection of the hygienist policies, which pointed to water in urban environments as a vector of epidemics and bad smell, which actually was related to the lack of maintenance and disuse of the system, resulting in stormwater and sewage flowing through the streets. The solution, at the time, was to hide and pipe it, actions that cause impacts till nowadays. The traditional systems, beside the high rate of urbanization and soil imperviousness, are insufficient to the great volume drained, causing floods and damages. Alternative approaches to stormwater management have shown superior results, such as the complementary applications of compensatory techniques and Low

${ }^{1}$ GUERRA, Rodrigo Augusto; GONÇALVES, Luciana Marcia. Águas pluviais urbanas: integração da drenagem sustentável ao Plano Diretor de Desenvolvimento Urbano (PDU). In: II SIMPÓSIO NACIONAL DE GESTÃO E ENGENHARIA URBANA: SINGEURB, 2019, São Paulo. Anais... Porto Alegre: ANTAC, 2019.
\end{abstract}


Impact Development (LID) principles. This article results in a technical-conceptual review of alternative urban stormwater drainage and its relationship with urban development, represented by Cities Master Plans. Most Brazilian cities have water management as subject of supplementary plans, hindering efficient and premeditated execution during urban development, often generating environmental, social and economic impacts.

Keywords: Stormwater, Urban drainage, Sustainable drainage, Urban planning, Cities Master Plan.

\section{INTRODUÇÃO}

A relação dos seres humanos, e consequentemente da cidade, com a água passou por diferentes momentos no decorrer dos anos, desde seu apreço - no início da vida nômade, pela agricultura e higiene possibilitadas - até os primeiros sistemas de evacuação de águas, integradamente ao desenvolvimento urbano - nas Idades Antiga e Média (BAPTISTA et al., $2011)$. A separação através da canalização surgiu pelas ideias higienistas, que relacionaram a presença da água a algo patogênico e fétido - o que, na realidade, relacionava-se à falta de manutenção dos sistemas de evacuação das águas pluviais e do esgoto, acarretando em seu desuso, deixando-as escorrer pelas ruas (BAPTISTA et al., 2011).

No século XIX, com o aumento exponencial da população urbana, a precária infraestrutura de controle das águas urbanas favoreceu o alastramento de epidemias pela Europa, mudando a relação do urbanismo e as águas citadinas, que passou a pregar o escoamento mais rápido possível (BAPTISTA et al., 2011). O crescimento continuou durante o século XX, e, em 2010, o Brasil chegava a 84,36\% da população vivendo em cidades (IBGE, 2010).

Devido à alta taxa de urbanização e ao aumento populacional urbano, foram necessários novos tratamentos do espaço citadino. Na legislação brasileira, o Estatuto da Cidade, de 2001, regulamenta os artigos 182 e 183 da Constituição Federal de 1988, e nele é apontado o Plano Diretor de Desenvolvimento Urbano (PDU) como o principal instrumento para 0 ordenamento territorial citadino. O planejamento municipal a partir do PDU e do zoneamento define o uso e ocupação dos espaços de modo a garantir o desenvolvimento dos cidadãos e o cumprimento da função social da cidade. A lei aponta normas a serem observadas pelos gestores municipais quanto a ordenação territorial, elaboração e execução das políticas urbanas (BARROS et al., 2010). Em 2003, com a criação do Ministério das Cidades - atualmente extinto -, houve maior apoio às cidades quanto a consolidação de modelos que englobasse saneamento, habitação e mobilidade urbana, com menções à cidade sustentável, apoiando a implementação da lei do Estatuto, de modo a facilitar o enfrentamento de questões sociais, ambientais e econômicas que afetam a vida de muitos brasileiros (FERNANDES, 2010).

\section{JUSTIFICATIVA}

Diante da dificuldade de implementação de abordagens alternativas de drenagem pluvial urbana e manejos integrados em obras de urbanização, verifica-se a necessidade de uma mais eficaz aproximação entre PDU e demais planos urbanos. Ou seja, não só objetivarem as mesmas premissas de redução de impactos, mas tratarem de diretrizes projetuais, que nem mesmos planos específicos têm apresentado.

A maioria das cidades que vêm desenvolvendo este modelo de planos integrados são grande porte, devido a exigências legais do Estatuto da Metrópole (FNEM, 2019). Entretanto, só o fazem pela urgência pelo número de problemas urbanos enfrentados e de pessoas afetadas. Tais planos são mais voltados a integrações territoriais e espaciais e menos a projetos urbanísticos, demonstrando a necessidade urgente do carácter integrador entre PDU e planos e projetos complementares. Cidades de pequeno e médio porte, apesar de não possuírem legislação que discipline a integração de planos, também apresentam problemas urbanos, necessitando de uma abordagem mais preventiva e corretiva.

A ausência de planos integrados resulta em problemas como enchentes e inundações, que 
provocam danos sociais, ambientais e econômicos, cuja origem pode estar nas ocupações em áreas próximas a mananciais e zonas de alagamento (TUCCl, 2002), ou por equipamentos urbanos de captação e controle das águas pluviais inadequados ou ineficientes, que ignoram os novos padrões de adensamento e desenvolvimento urbano.

\section{OBJETIVO}

Visa-se contribuir na compreensão da importância da abordagem integrada da drenagem sustentável e do planejamento urbano. Por meio da elaboração de premissas projetuais que visam o planejamento urbano sustentável, principalmente do ponto de vista das águas pluviais, nas elaborações e revisões de PDUs. Como resultado, apresentam-se condicionantes para a aprovação de loteamentos e zoneamentos urbanos integrado às diretrizes de drenagem urbana e manejo das águas pluviais, objetivando a diminuição dos problemas urbanos ocasionados pela visão higienista das águas independentemente ao projeto da cidade. O estabelecimento de novas relações entre águas urbanas e habitantes citadinos diminui os impactos sociais, ambientais e econômicos, vindo ao encontro dos objetivos almejados pelos novos PDUs. A integração formal e legal desses instrumentos de desenho da cidade pode inverter a atual rejeição apresentada pelos habitantes citadinos em relação às águas da chuva e dos córregos urbanos.

\section{MATERIAL E MÉTODOS}

As informações sobre técnicas compensatórias quanto a águas pluviais foram obtidas do banco de dados do grupo G-HIDRO, do Programa de Pós-Graduação em Engenharia Urbana da Universidade Federal de São Carlos, o qual realizou pesquisas científicas em estruturas construídas em escala real no campus. Também foram consultadas bibliografias brasileiras e estrangeiras nas áreas de: drenagem pluvial urbana (TUCCI); técnicas compensatórias em drenagem pluvial urbana (BAPTISTA); planejamento urbano sustentável (Low Impact Development Design Strategies, de Prince George's County, Maryland, EUA). As legislações brasileiras consultadas relativas ao planejamento urbano e gestão de cidades foram: Estatuto da Cidade; Programa de Drenagem Urbana Sustentável e Plano de Desenvolvimento Urbano Integrado. Após estudo, relacionou-se as abordagens teóricas e técnicas do manejo das águas pluviais urbanas e o planejamento territorial, apresentando o entendimento espacial necessário ao desenvolvimento de abordagens alternativas para a drenagem urbana.

\section{DESENVOLVIMENTO}

Na medida em que mais pessoas habitam a cidade, mais urbanizada e impermeável ela se transforma, devido ao atual padrão de ocupação, ocasionando mudanças no ciclo hidrológico (Figura 1). 
Figura 1 - Balanço hídrico em ocupações
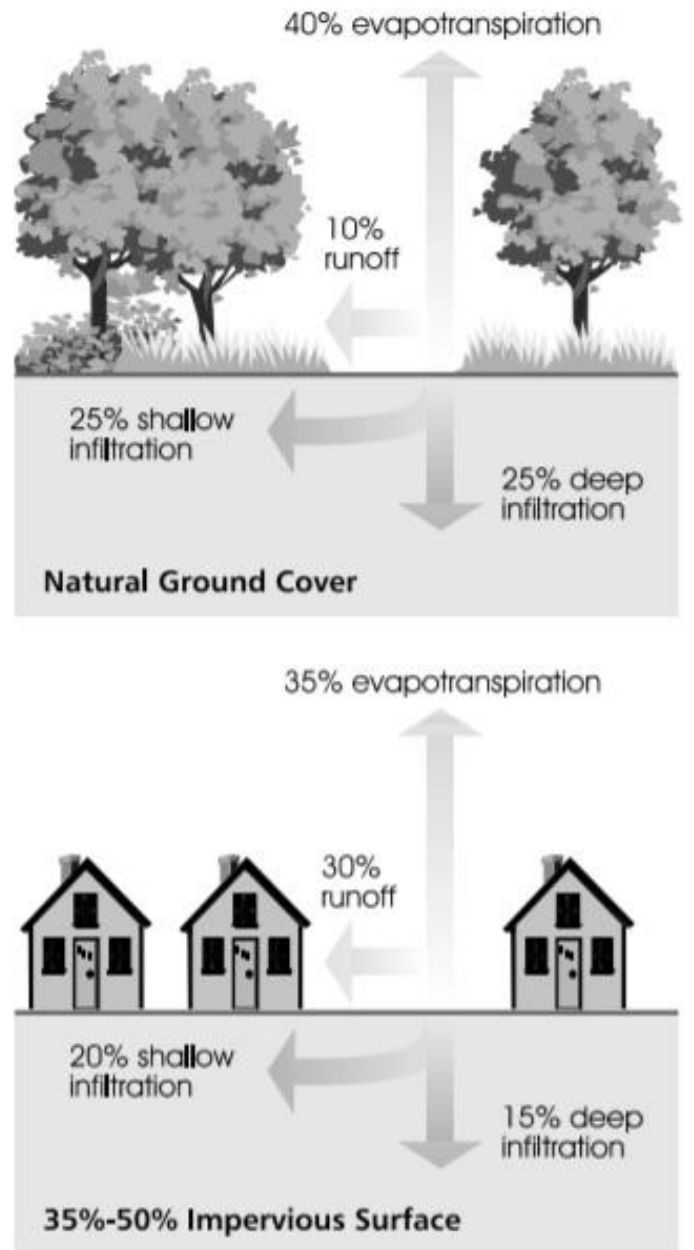
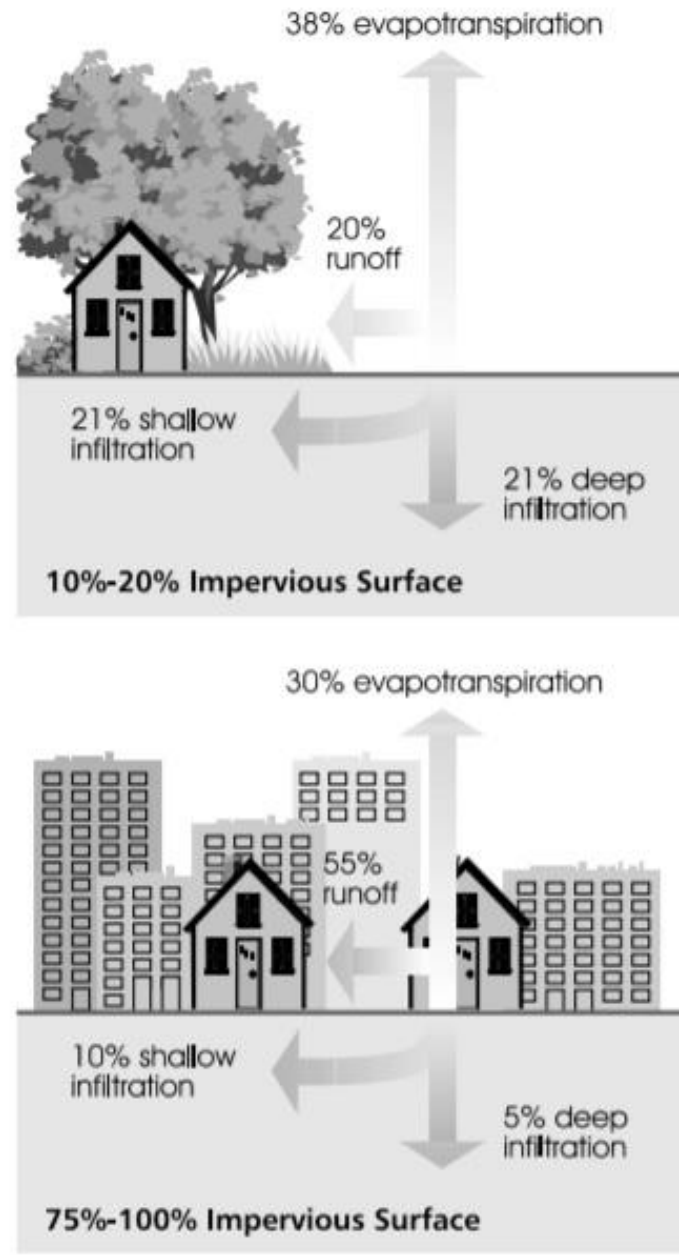

Fonte: PRINCE GEORGE'S COUNTY (1999)

Áreas à jusante são as mais atingidas, pois uma enorme quantidade de poluição e água chega rapidamente, através de tubulações, causando impactos sociais, econômicos e ambientais (TUCCl, 2002) (OLIVEIRA, 2018). Reduzindo-se a taxa de infiltração da água no solo, diminui-se o abastecimento de aquíferos e aumenta-se a quantidade e velocidade de seu escoamento superficial; e sua não retenção reduz a evapotranspiração natural - processo essencial para o balanço hídrico, auxiliado por folhagens e solos (OLIVEIRA, 2018).

Apesar de serem mais evidentes nos grandes aglomerados urbanos, os problemas de drenagem também atingem cidades de pequeno e médio porte, e, com o passar do tempo, o sistema tradicional de drenagem pluvial vem se demonstrando ineficaz no combate a enchentes e inundações, influenciando na qualidade de vida dos habitantes e até dos cursos d'água (VENTURA et al., 2019). A partir desta situação, novas posturas quanto a técnicas e abordagens alternativas ao sistema clássico de drenagem pluvial urbana estão em estudo e sendo empregadas (Figura 2), de modo a tornar mais natural e prolongada a presença da água pluvial nos espaços urbanos, como:

- Desenvolvimento de Baixo Impacto (LID);

- Técnicas Compensatórias (TCs);

- Desenho Urbano Sensível à Água (WSUD);

- Práticas de Gestão Integrada (BMPs). 
Figura 2 - Comparação de sistemas mecânicos (tradicionais) e alternativos

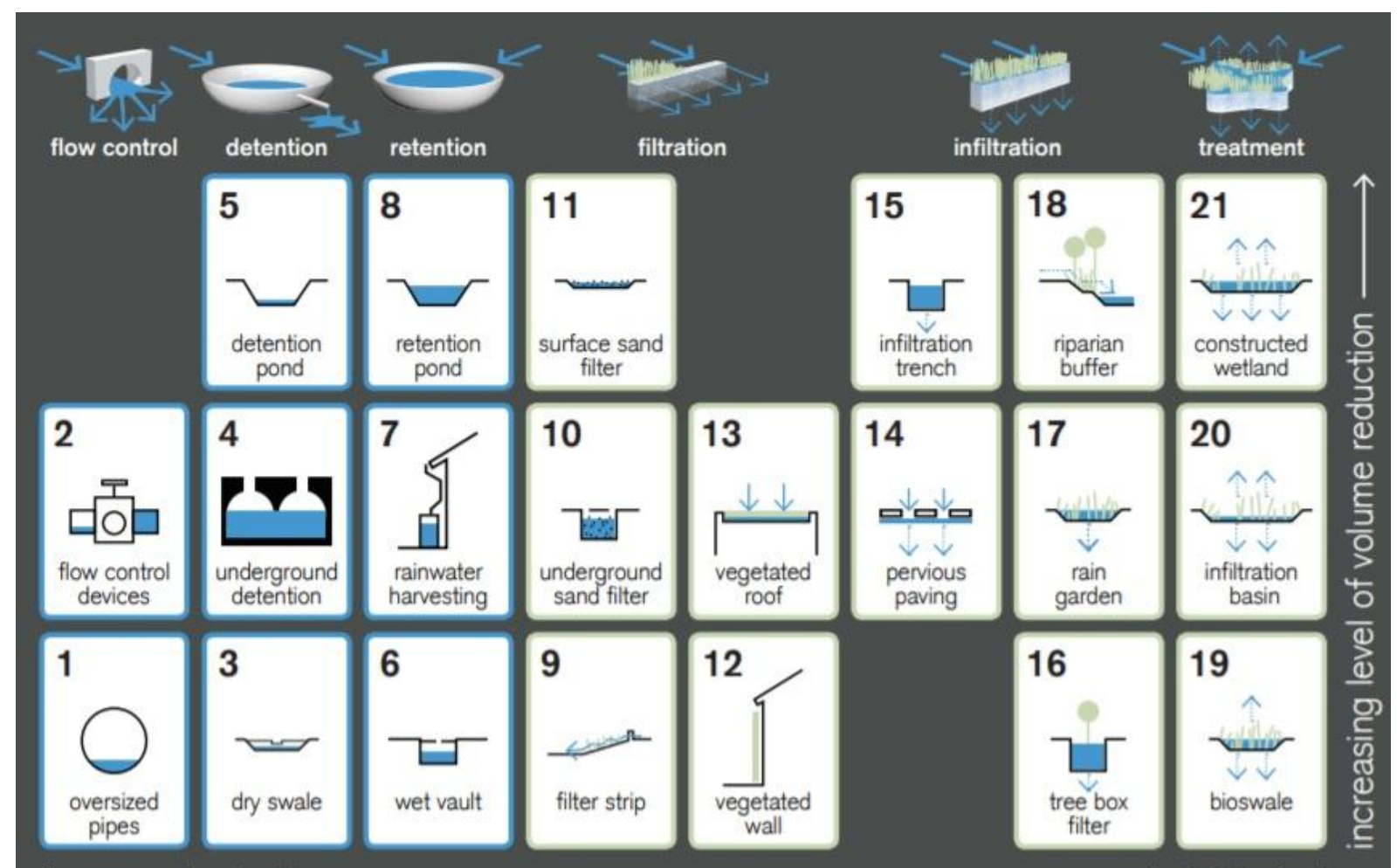

from mechanical

LID facilities menu

Fonte: UNIVERSITY OF ARKANSAS COMMUNITY DESIGN CENTER (2010)

Para implementação de abordagens que possibilitem maior infiltração das águas pluviais no solo e tornem os escoamentos superficiais visíveis - ou seja, não canalizados e enterrados -, são requeridos espaços urbanos disponíveis. O acesso à terra urbana atualmente está relacionado diretamente a preço (MARICATO, 2010), tornando a espacialização de projetos e planos tema obrigatório a PDUs, principalmente por meio do zoneamento. Portanto, o manejo da água pluvial urbana precisa ser integrado ao ordenamento territorial.

As técnicas alternativas desenvolvidas devem ser discutidas nos PDUs, de modo que suas aplicabilidades atinjam a cidade real. Existem cidades brasileiras com TCs executadas, porém a minoria as abordava em seu PDU, sendo consideradas soluções momentâneas para enchentes. A gestão pública e os habitantes da cidade precisam compreender a necessidade da integração das águas pluviais aos planos urbanos desde seus princípios norteadores.

No Brasil, não há regulamentações quanto ao uso das técnicas alternativas, porém o extinto Ministério das Cidades estimulava a utilização do LID no desenvolvimento urbano através do Programa Drenagem Urbana Sustentável (BRASIL, 2006). Entretanto, a maior parte dos municípios brasileiros carece de planos específicos, como o Plano Diretor de Drenagem Urbana (PDDU), desvinculando as obras municipais de ações pré-planejadas. Em 2008, 78,6\% dos municípios brasileiros tinha serviços de drenagem urbana, enquanto em municípios de até 20 mil habitantes essa porcentagem cai para $74,7 \%$, e chegava a $100 \%$ naqueles com mais de 300 mil habitantes (IBGE, 2011). Entretanto, somente 12,7\% dos municípios declararam ter algum dispositivo coletivo de detenção e amortecimento da vazão das águas pluviais urbanas. A pesquisa apontou a criação de PDUs como um passo ao melhoramento do setor, de modo que deveriam ser considerados aspectos hidrológicos locais e definidos dimensionamentos e soluções alternativas para ocupação do solo. 
Atribuindo ao PDU a recomendação e defesa do uso do manejo sustentável das águas urbanas, reforçam-se as motivações para a realização e revisão periódica dos PDUs, já que trata do gerenciamento dos espaços urbanos. Porém, quase metade dos municípios brasileiros não possuía PDUs em 2016 (Figura 3). Se forem considerados como aprovados os que, à época, estavam em aprovação, calcula-se que aproximadamente $40 \%$ dos municípios não possuem PDU.

Figura 3 - Percentual de municípios por situação do PDU, Brasil, 2005/2015

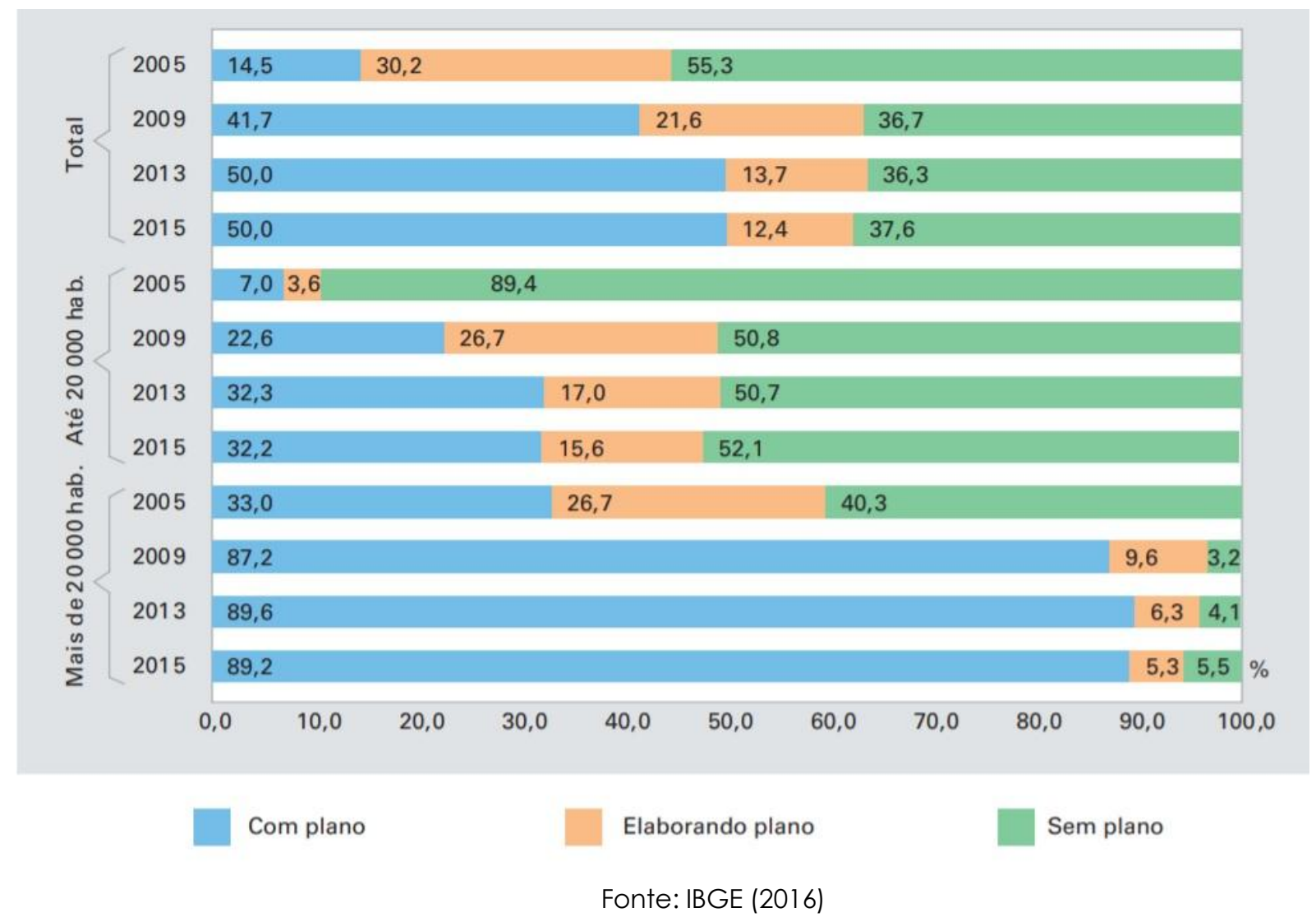

Quando realizada, a abordagem das águas pluviais no PDU é, em sua maioria, extremamente superficial, bem como a de diversos outros setores relacionados ao desenvolvimento urbano, tornando visível a falta de instrumentos urbanísticos para o controle ambiental e especialmente da drenagem no planejamento das cidades. Algumas cidades brasileiras implantaram iniciativas de compensação quanto a áreas impermeabilizadas ou incentivo ao uso de águas pluviais (CRUZ et al., 2007), porém a maioria continua a reproduzir o sistema tradicional de drenagem, sem instrumentos reguladores nos PDUs. A inclusão das técnicas alternativas da drenagem urbana pluvial se torna muito mais eficaz quando abordada integradamente ao PDU, já que este é o mecanismo mais eficiente e diretamente relacionado com a produção e manejo do espaço urbanizado. Para que novos loteamentos e regeneração de espaços consolidados sejam projetados simultaneamente ao manejo das águas pluviais, deve-se realizar o apontamento de requisitos na forma de diretrizes e instrumentos urbanísticos, a fim de integrar tais conceitos na construção de novas áreas.

\section{CONCLUSÕES}

O planejamento de urbanizações precisa ser atualizado, pois situações resultantes de comportamentos anteriores geram constantes impactos ambientais, sociais e econômicos. A busca por alcance de indicadores positivos de sustentabilidade está cada vez mais presente no planejamento de cidades, e mostra caminhos alternativos às tradicionais técnicas. Um dos conjuntos de indicadores é a necessidade da abordagem do manejo sustentável de águas 
pluviais urbanas nos PDUs, de modo a garantir, dentre outros, a reserva de terra urbanizada destinada a estruturas de drenagem sustentável, possibilitando a minimização de danos causados por enchentes e descontroles de fluxos superficiais de água.

Foi demonstrado que abordagens alternativas de drenagem urbana necessitam de espaços exclusivos ou integrados a outros usos. Sendo assim, o PDU pode garantir sua destinação por meio do zoneamento e dos demais instrumentos de uso e ocupação do solo. Portanto, as abordagens de definição de áreas de uso específico relacionaram a drenagem urbana à função social da cidade.

\section{AGRADECIMENTOS}

Agradecimentos à agência de financiamentos CAPES.

\section{REFERÊNCIAS}

BAPTISTA, M. B.; NASCIMENTO, N. O.; BARRAUD, S. Técnicas Compensatórias em Drenagem

Urbana. Porto Alegre: Associação Brasileira de Recursos Hídricos, 2011. 318 p.

BARROS, A. M. F. B.; CARVALHO, C. S.; MONTANDON, D. T. O Estatuto da Cidade comentado: Lei No 10. 257 de 10 de julho de 2001. In: CARVALHO, C. S.; ROSSBACH, A. O Estatuto da

Cidade: comentado. São Paulo: Ministério das Cidades: Aliança das Cidades, 2010.

Disponível em:

http://www.cidades.gov.br/images/stories/ArquivosSNPU/Biblioteca/PlanelamentoUrbano/Es tatutoComentado_Portugues.pdf. Acesso em: 9 abr. 2019.

BRASIL. Constituição Federal de 1988. Constituição da República Federativa do Brasil. Brasília, DF: Senado Federal: Centro Gráfico, 1988. 292 p.

BRASIL. Estatuto da Cidade: Lei 10.257/2001 que estabelece diretrizes gerais da política urbana. Brasília, Câmara dos Deputados, 2001, $1^{a}$ Edição.

BRASIL. Programa Drenagem Urbana Sustentável. Ministério das Cidades. 2006. Manual para apresentação de propostas. 23 p. 2006.

CRUZ, M. A. S.; SOUZA, C. F.; TUCCI, C. E. M. Controle da Drenagem Urbana No Brasil: avanços e mecanismos para sua sustentabilidade. In: XVII Simpósio Brasileiro de Recursos Hídricos, 2007, São Paulo. $8^{\circ}$ Simpósio de Hidráulica e Recursos Hídricos dos Países de Língua Oficial Portuguesa. São Paulo: Associação Brasileira de Recursos Hídricos, 2007. Disponível em:

https://www.abrh.org.br/SGCv3/index.php?PUB=3\&ID=19\&SUMARIO=4674\&ST=controle_da_d renagem_urbana_no_brasil_avancos_e_mecanismos_para_sua_sustentabilidade. Acesso em: 28 mar. 2019.

FERNANDES, E. O Estatuto da Cidade e a ordem jurídico-urbanística. In: CARVALHO, C. S.; ROSSBACH, A. O Estatuto da Cidade: comentado. São Paulo: Ministério das Cidades: Aliança das Cidades, 2010. Disponível em:

http://www.cidades.gov.br/images/stories/ArquivosSNPU/Biblioteca/PlanelamentoUrbano/Es tatutoComentado_Portugues.pdf. Acesso em: 9 abr. 2019.

FÓRUM NACIONAL DE ENTIDADES METROPOLITANAS - FNEM. Plano de Desenvolvimento Urbano Integrado (PDUI). São Paulo, 2019. Disponível em: http://fnembrasil.org/pdui/. Acesso em: 23 mar. 2019.

INSTITUTO BRASILEIRO DE GEOGRAFIA E ESTATÍSTICA - IBGE. Sinopse do Censo Demográfico 2010. [S. I.], 2010. Disponível em:

https://ww2.ibge.gov.br/home/estatistica/populacao/censo2010/sinopse/sinopse_tab_brasil 
_zip.shtm. Acesso em: 25 mar. 2019.

INSTITUTO BRASILEIRO DE GEOGRAFIA E ESTATÍSTICA - IBGE. Pesquisa de Informações Básicas Municipais: perfil dos municípios brasileiros. Rio de Janeiro: Ministério do Planejamento, Orçamento e Gestão, 2016. Pesquisa. Disponível em:

https://biblioteca.ibge.gov.br/visualizacao/livros/liv95942.pdf. Acesso em: 28 mar. 2019.

MARICATO, E. O Estatuto da Cidade Periférica. In: CARVALHO, C. S.; ROSSBACH, A. O Estatuto da Cidade: comentado. São Paulo: Ministério das Cidades: Aliança das Cidades, 2010. Disponível em:

http://www.cidades.gov.br/images/stories/ArquivosSNPU/Biblioteca/PlanelamentoUrbano/Es tatutoComentado_Portugues.pdf. Acesso em: 9 abr. 2019.

PRINCE GEORGE'S COUNTY. Low-Impact Development Design Strategies: an integrated design approach. Maryland: Department of Environmental Resource, 1999. Disponível em: https://www.princegeorgescountymd.gov/1478/Design-Manuals. Acesso em: 28 mar. 2019.

TUCCl, C. E. M. Gerenciamento da drenagem urbana. RBRH - Revista Brasileira de Recursos Hídricos, Porto Alegre, p. 5-27, jan./mar. 2002. Disponível em: https://www.abrh.org.br/SGCv3/index.php?PUB=1\&ID=99\&SUMARIO=1583. Acesso em: 23 mar. 2019.

UNIVERSITY OF ARKANSAS COMMUNITY DESIGN CENTER. LID - Low Impact Development: a design manual for urban areas. Fayetteville: University of Arkansas Press, 2010. Disponível em: http://uacdc.uark.edu/work/low-impact-development-a-design-manual-for-urban-areas. Acesso em: 24 mar. 2019.

VENTURA, K. S.; VAZ FILHO, P.; GONÇALVES, L. M. Gestão integrada de projetos sustentáveis em municípios de médio porte. In: ROSIN, J. A. R. G.; BENINI, S. M. Cidade Sustentável: um conceito em construção. Tupã/SP: ANAP, 2019. 